\title{
Identification of Calreticulin as a Prognosis Marker and Angiogenic Regulator in Human Gastric Cancer
}

\author{
Chiung-Nien Chen, MD, $\mathrm{PhD}^{1}$, Cheng-Chi Chang, $\mathrm{PhD}^{2}$, Ting-En $\mathrm{Su}^{3}$, Wen-Ming $\mathrm{Hsu}, \mathrm{MD}, \mathrm{PhD}^{1}$ \\ Yung-Ming Jeng, $\mathrm{MD}^{4}$, Ming-Chih $\mathrm{Ho}$, MD, $\mathrm{PhD}^{1}$, Fon-Jou Hsieh, $\mathrm{MD}^{5}$, Po-Huang Lee, MD, $\mathrm{PhD}^{1}$, \\ Min-Liang Kuo, $\mathrm{PhD}^{\mathbf{6}}$, Hsinyu Lee, $\mathrm{PhD}^{3}$, and King-Jen Chang, $\mathrm{MD}, \mathrm{PhD}^{1}$ \\ ${ }^{1}$ Department of Surgery, Angiogenesis Research Center, National Taiwan University Hospital and College of Medicine, \\ 7 Chung-Shan S. Road, Taipei 100, Taiwan; ${ }^{2}$ Department of Dentistry, School of Medicine, National Taiwan University, \\ Taipei, Taiwan; ${ }^{3}$ Department of Life Science, Institute of Zoology, Angiogenesis Research Center, National Taiwan \\ University, 1 Roosevelt Rd., Sec. 4, Taipei 106, Taiwan; ${ }^{4}$ Department of Pathology, National Taiwan University Hospital, \\ Taipei, Taiwan; ${ }^{5}$ Department of Obstetrics, National Taiwan University Hospital, Taipei, Taiwan; ${ }^{6}$ Department of \\ Toxicology, School of Medicine, National Taiwan University, Taipei, Taiwan
}

\begin{abstract}
The purpose of this study was to identify genes of interest for a subsequent functional and clinical cohort study using complementary (c)DNA microarrays. cDNA microarray hybridization was performed to identify differentially expressed genes between tumor and nontumor specimens in 30 gastric cancer patients. Subsequent functional studies of the selected gene were carried out, including cell cycle analysis, cell migration analysis, analyses of vascular endothelial growth factor (VEGF) and placenta growth factor (PIGF), and oligo-microarray studies using two pairs of stable cell lines of the selected gene. Another independent cohort study of 79 gastric cancer patients was conducted to evaluate the clinical significance of the selected gene in human gastric cancer. Calreticulin (CRT) was selected for further investigation. Two pairs of stable cell lines of CRT overexpression and CRT knockdown were constructed to perform functional studies. CRT enhanced gastric cancer cell proliferation and migration. Overexpressed CRT upregulated the expression and secretion of PIGF and VEGF. CRT had a reciprocal effect on connective tissue growth factor (CTGF) expression. Positive immunohistochemical staining of calreticulin was significantly correlated with high microvessel density
\end{abstract}

Electronic supplementary material The online version of this article (doi:10.1245/s10434-008-0243-1) contains supplementary material, which is available to authorized users.

(C) Society of Surgical Oncology 2008

First Received: 1 September 2008;

Published Online: 3 December 2008

H. Lee, $\mathrm{PhD}$

e-mail: hsinyu@ntu.edu.tw
(MVD) $(p=0.014)$, positive serosal invasion $(p=0.013)$, lymph node metastasis $(p=0.002)$, perineural invasion $(p=0.008)$, and poor patient survival $(p=0.0014)$. Multivariate survival analysis showed that CRT, MVD, and serosal invasion were independent prognosticators. We conclude that CRT overexpression enhances angiogenesis, and facilitates proliferation and migration of gastric cancer cells, which is in line with the association of CRT with MVD, tumor invasion, lymph node metastasis, and survival in gastric cancer patients.

Calreticulin overexpression enhances angiogenesis, and facilitates proliferation and migration of gastric cancer cells, and is associated with microvessel density, tumor invasion, lymph node metastasis, and survival in gastric cancer patients.

For the past 50 years, gastric cancer has been one of the ten most frequent cancers and the second leading cause of cancer-related death in the world. In Taiwan, it is the fifth most common cause of cancer-related deaths, accounting for $6.3 \%$ of all cancer deaths. Patients whose gastric cancer is detected early have a good prognosis, and those with advanced disease show a poor and unpredictable prognosis after curative resection. ${ }^{1,2}$ Therefore, much attention has been given to endogenous factors of these tumors, which appear to be responsible for tumor cell growth, progression, and invasion. Identifying such endogenous factors should lead not only to a better understanding of the processes of tumor cell progression and metastasis, but may also provide new strategies for developing agents that specifically suppress this process. 
Recent excellent advances in the DNA microarray have systematically enabled us to visualize gene expression profiles in human tumors. ${ }^{3-5}$ This technique may provide another possibility to evaluate genes differentially expressed between normal and tumor tissues, and select hotspot genes for further clinical study.

In this study, an in-house nylon membrane complementary (c)DNA microarray, which included 328 genes known as angiogenesis-related genes, was constructed to select molecules of interest for gastric cancer for further functional and clinical study.

\section{MATERIALS AND METHODS}

\section{Summary of Methodologies}

The study was initiated by using microarray to select the most commonly overexpressed genes. Calreticulin was selected and was confirmed using a semiquantitative reverse-transcription polymerase chain reaction (RT-PCR) and immunohistochemical staining. Two pairs of stable cell lines of CRT overexpression and knockdown were constructed to investigate the effects of CRT on cancer cell migration, proliferation, and expression of vascular endothelial growth factor (VEGF) and placenta growth factor (PlGF), the two angiogenic factors closely related to gastric cancer. ${ }^{6}$ Subsequent oligo-microarray studies were also performed to select CRT-regulated genes using two pairs of stable cell lines. Finally, another 79 patients were enrolled to evaluate the association of CRT expression with MVD and patient survival.

\section{Gene Selection Patients and Samples for cDNA Microarray}

The 30 pairs of tumor and nontumor specimens were obtained from 30 patients with gastric cancer who underwent a curative intent gastrectomy with D2 lymphadenectomy at the National Taiwan University Hospital. Studies using human tissues were approved by and conducted in accordance with the policies of the institutional review board. RNAs of these 30 pairs of the specimens were extracted and were used to perform microarray experiments using a cDNA microarray made of nylon membrane spotted on 328 known angiogenesis-related genes; the details have been described previously. ${ }^{7,8}$ The gene expression ratio of tumor to normal tissue in 30 pairs of microarrays was calculated.

\section{Evaluation of Microvessel Density}

Paraffinized sections of gastric cancer tissues were stained for the endothelial cell antigen CD34 using labeled streptavidin-biotin after antigen retrieval. Experimental procedures were performed as described previously. ${ }^{6}$ Microvessels in the area with the highest number of discrete microvessels were counted in a $400 \times$ field. Three separate intense neovascularized areas were assessed, and the mean was calculated as the MVD of each tumor evaluated.

\section{Immunohistochemical Staining of CRT}

The paraffinized sections of gastric cancer were stained for CRT with an anti-CRT monoclonal antibody (Santa Cruz Biotechnology) at a dilution of 1:40 using the same methods as microvessel staining described above. The positive staining of a cancer cell implies that brownish granular staining was present primarily in the cytoplasm and perinuclear area of the cell. More than $10 \%$ cells positively stained was graded as positive.

\section{Association of CRT Expression and Clinical Outcome}

Seventy-nine patients with gastric cancer, who had undergone curative-intent gastrectomy with D2 lymphadenectomy at our institution from July 1995 to March 1999, were included in this study. Subtotal and total gastrectomy was performed in 50 and 29 patients, respectively. They were staged according to the tumor-node-metastasis (TNM) system: 8 patients were stage Ia, 7 were stage Ib, 7 were stage II, 31 were stage IIIa, and 26 were stage IIIb. No patient had received chemotherapy and radiotherapy before surgery. Clinicopathologic factors including age, gender, gross types of tumors (Borrmann classification), histologic types of tumors (Lauren classification), depth of tumor invasion, status of lymph node metastasis documented with histologic findings, and MVD were reviewed. Patient survival was followed up for 3-133 months after surgery. Three patients who died of surgical complications were excluded from the survival statistics. The association between CRT expression and the aforementioned clinical outcomes was evaluated.

\section{Construction of Stable Clones}

The AGS human gastric cancer cell line was purchased from BCRC (Hsinchu, Taiwan) to construct two pairs of stable cell lines of CRT overexpression (pEGFP-c1 and CRT-pEGFP-c1 stable clones) and knockdown (shRNAcontrol and CRT-shRNA stable clones). Details are shown in the Supplemental Material.

\section{Cell Cycle Analysis}

Cells were trypsinized and resuspended in $1 \mathrm{ml}$ phosphate buffered saline (PBS). Propidium iodide (PI) was added to 

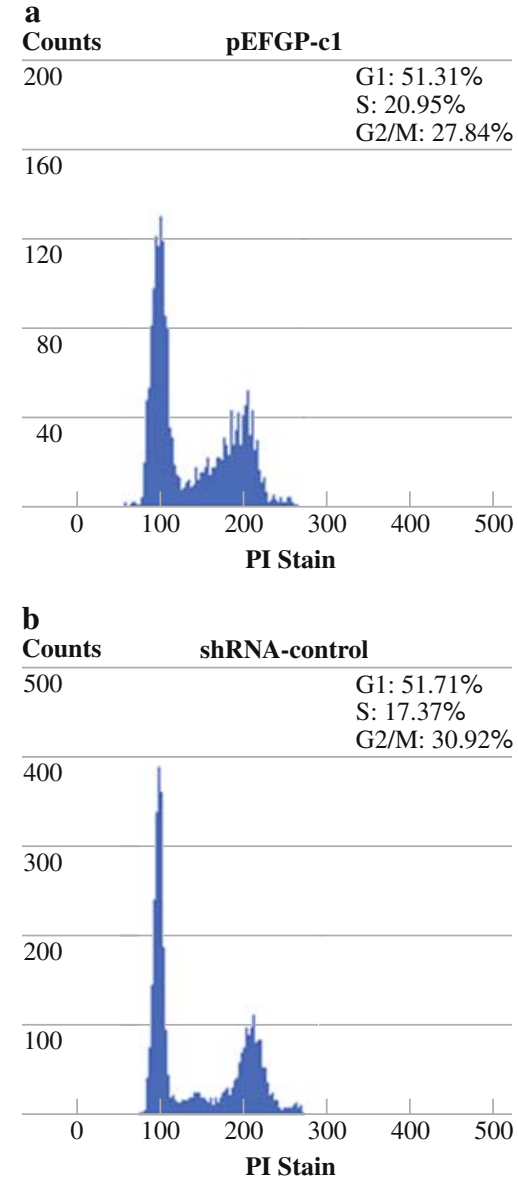
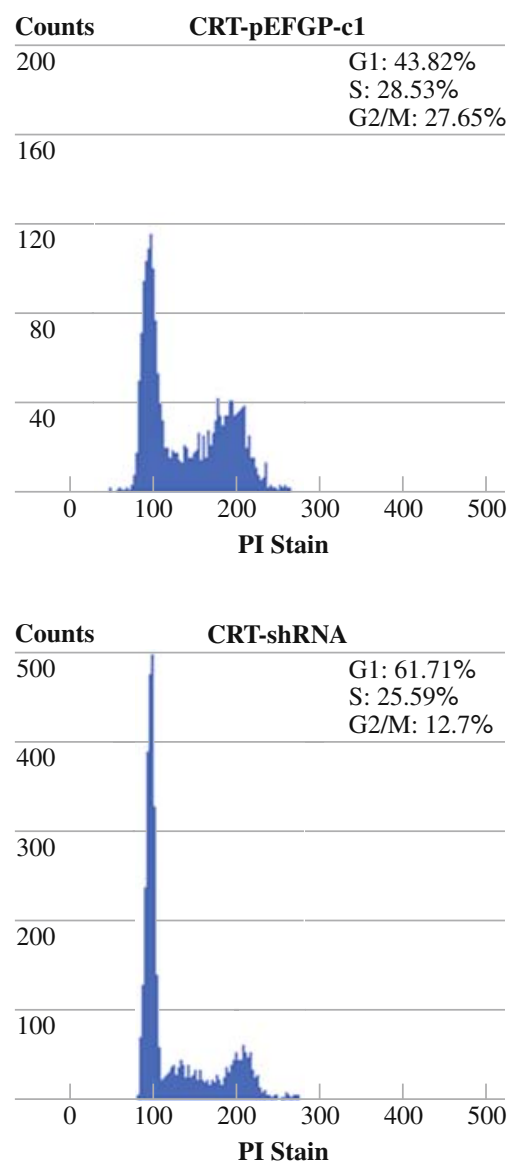

Cells Entered S and G2/M Phases (Relative Fold to Control)

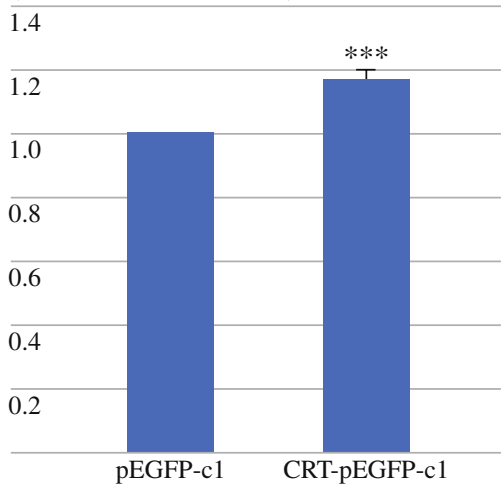

Cells Entered S and G2/M Phases (Relative Fold to Control)

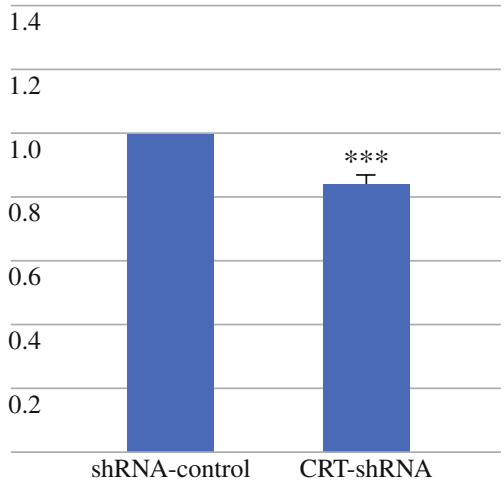

c

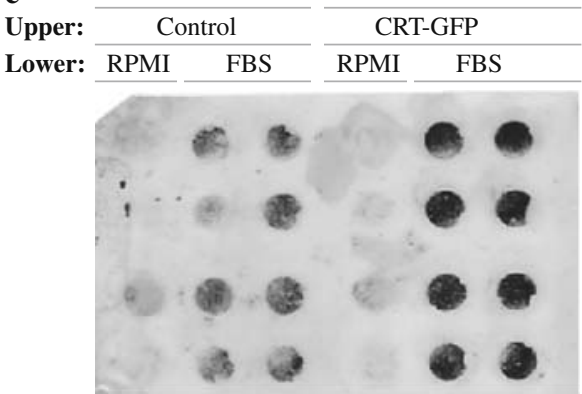

Cell Migration

(Relative Fold to Control)
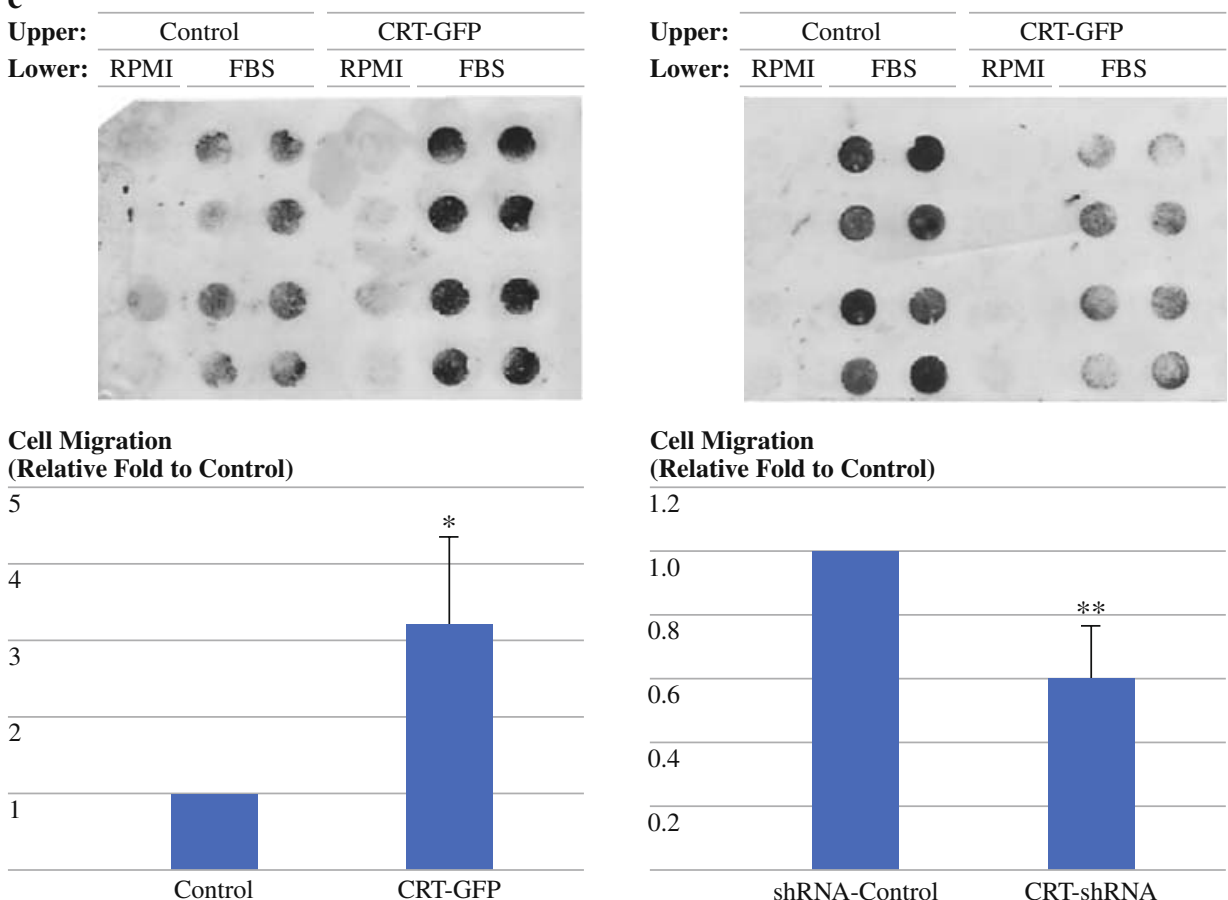

Cell Migration

(Relative Fold to Control)

1.2

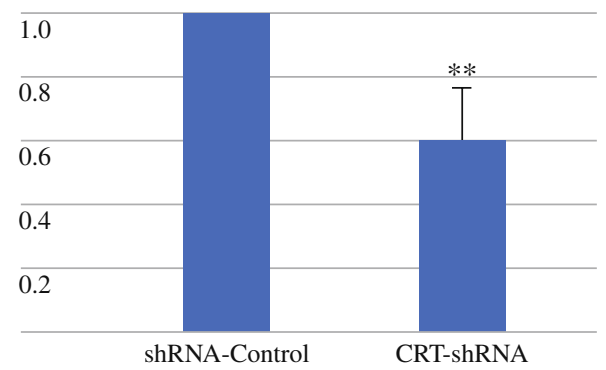


4 FIG. 1 Cell cycle analysis and cell migration study in of calreticulin (CRT)-overexpressing and CRT-knockdown stable cell lines. a CRTpEGFP-c1 cells showed proportionally fewer cells in the G1 phase and more cells in the $\mathrm{S}$ and G2/M phases compared with pEGFP-c1 cells. b CRT-shRNA cells showed proportionally more cells in the G1 phase and fewer cells in the $\mathrm{S}$ and $\mathrm{G} 2 / \mathrm{M}$ phases compared with shRNA-control cells. c CRT-overexpressing cells had a higher migration rate while CRT-knockdown cells had a lower migration rate compared with the control. These results were confirmed by at least three independent experiments. Each bar of the histogram represents quantified results as the mean value \pm standard deviation (SD) $(* p<0.05, * * p<0.01, * * * p<0.001)$

the suspensions and then incubated in a $37^{\circ} \mathrm{C}$ water bath for $20 \mathrm{~min}$ in the dark. PI-stained cells were analyzed by flow cytometry, and the percentages of different phases were automatically analyzed by Partec FloMax software.

\section{Cell Migration Assay}

Migration rates of different cell lines were assayed in a modified Boyden's chamber (Neuro Probe, Gaithersburg, MD, USA). Cell suspensions at $50 \mu \mathrm{l}\left(2 \times 10^{4} /\right.$ well $)$ were loaded in the upper chamber. Migrating cells were fixed and quantified by a colorimetric measurement using crystal violet staining with TotalLab v2.01 software.

\section{Oligo-Microarray Experiments for Selecting CRT-Regulated Genes}

RNA isolated from CRT-pEGFP-c1 and CRT-shRNA stable clones was labeled with $\mathrm{Cy} 5$, and RNA from pEGFP-c1 and shRNA-control stable clones was labeled with Cy3. Total RNA $(0.5 \mu \mathrm{g})$ was amplified, Cy-labeled, and fragmented. Correspondingly fragmented labeled cRNA was then pooled and hybridized to the Agilent human 1A v2 oligo-microarray (Agilent Technologies, Santa Clara, CA, USA). The microarrays were scanned with an Agilent microarray scanner (Agilent Technologies, Santa Clara, CA, USA). Scanned images were analyzed by Feature extraction 9.1 software (Agilent Technologies, Santa Clara, CA, USA). The data were subsequently normalized by rank consistency filtering with the LOWESS method.

\section{Real-Time PCR Quantification of VEGF, PlGF, and Connective Tissue Growth Factor (CTGF) mRNAs of Stable Cell Lines}

cDNAs were synthesized with $2 \mu \mathrm{g}$ total RNA and an oligo-dT primer using ReverTra Ace reverse transcriptase. Quantitative (q)PCR was carried out using the iCycler iQ Real-Time detection system (Bio-Rad, Hercules, CA, USA) with the DNA double-stranded specific
SYBR Green I dye for detection. qPCR was performed using primers specific for glyceraldehyde 3-phosphate dehydrogenase (GAPDH) (forward; 5'-GGT GGT CTC CTC TGA CTT CAA $\mathrm{C}$ and reverse: $5^{\prime}$-TCT CTC TTC CTC TTG TGT TCT TG), CRT (forward: $5^{\prime}$-GTC GAT GTT CTG CTC ATG TTT C and reverse: $5^{\prime}$-AAG TTC TAC GGT GAC GAG GAG), CTGF (forward: $5^{\prime}$-GCC TCT TCT GTG ACT TCG and reverse: $5^{\prime}$-TCG TCT GGA AGG ACT CTC), and PlGF (forward: 5'-AAT GCC TCG CTC CCT TCA AGA C and reverse: $5^{\prime}$-GGT CTG TGG CTG GCT TCT CTC). For quantification, the target gene was normalized to the internal standard gene, GAPDH.

\section{Western Blotting for VEGF and CTGF Protein Expression in Stable Cell Lines}

Equal amounts of samples $(30 \mu \mathrm{g})$ were subjected to Western blotting by incubation with rabbit anti-CRT antibody (1: 5000 dilution), actin, or CTGF for $2 \mathrm{~h}$. Membranes were washed, then incubated with horseradish peroxidase-conjugated polyclonal goat anti-rabbit or rabbit anti-goat secondary antibodies (1:5,000 dilution) for $1 \mathrm{~h}$. Immunoreactive bands were quantified with TotalLab V2.01 software.

Enzyme-Linked Immunosorbent Assay (ELISA) for VEGF and PlGF Proteins in the Supernatant of Stable Cell Lines

Cells were plated at $5 \times 10^{5} /$ well in six-well plates. Conditioned media were collected and immediately analyzed using an ELISA kit specific for human VEGF (Biosource, Camarillo, CA, USA) and PlGF (R\&D Systems, Minneapolis, MN, USA) following the manufacturer's protocol. VEGF and PIGF concentrations were normalized to the cell number.

\section{Statistical Analysis}

Experimental data were statistically analyzed using Student's $t$-test. Each result was obtained from at least three independent experiments, and a value of $p<0.05$ was considered statistically significant. Fisher's exact probability test and chi-squared test were used for the statistical analysis of the expression of CRT with traditional clinical outcome. Survival was calculated using Kaplan-Meier method, and differences were analyzed by the log-rank test. A multivariate survival analysis was performed using the Cox proportional hazards model to investigate the independent prognostic factors. Statistical significance was defined as $p<0.05$. 
a

PIGF mRNA Expression

(Relative Fold to Control)

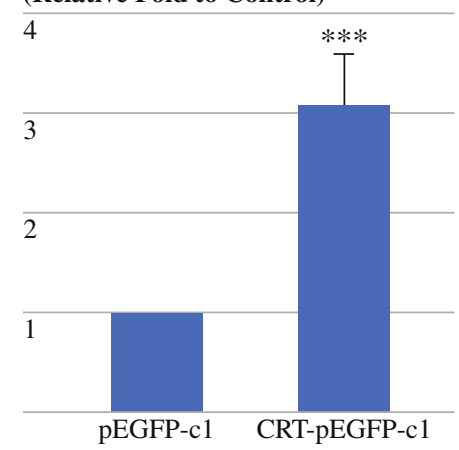

d

VEGF A mRNA Expression

(Relative Fold to Control)

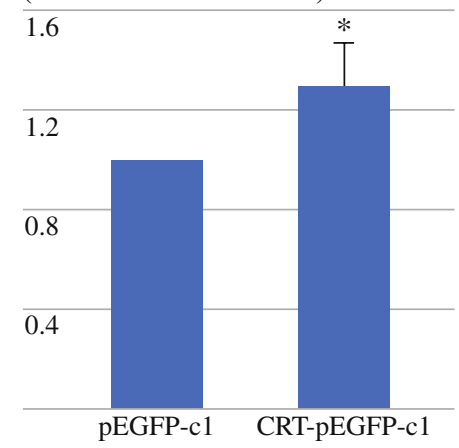

\section{b}

PIGF mRNA Expression

(Relative Fold to Control)

1.6

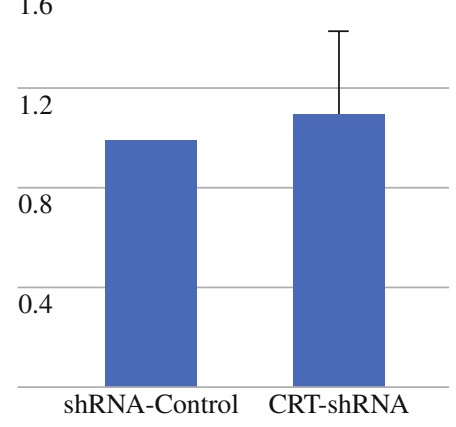

e

VEGF A mRNA Expression

(Relative Fold to Control)

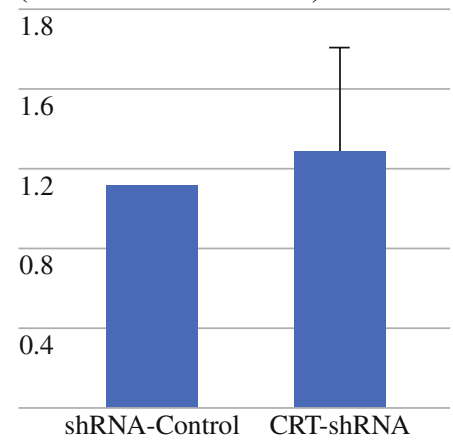

c

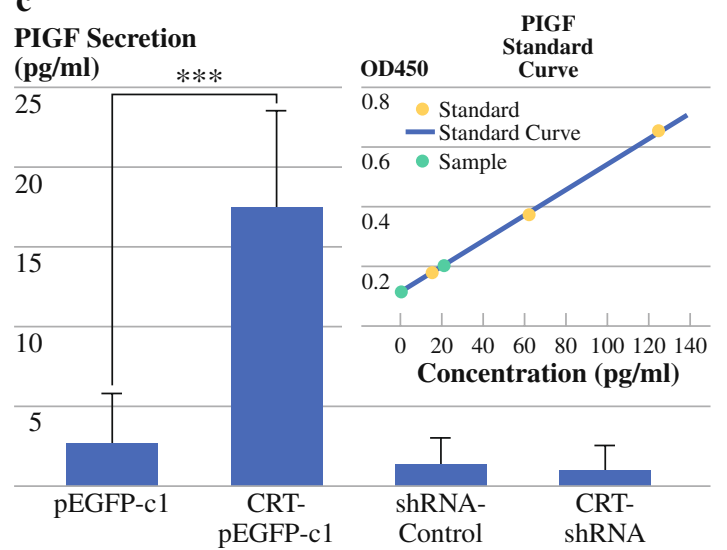

f

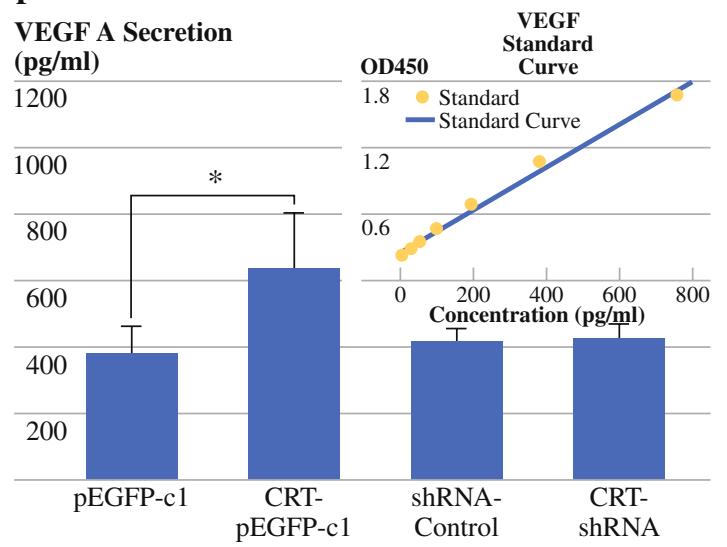

g

\begin{tabular}{cccc}
\hline \multicolumn{2}{c}{ Cell Lysate } & \multicolumn{2}{c}{ Conditioned Media } \\
\cline { 5 - 6 } pEGFP-c1 & pEGFP-c1 & & CRT- \\
& pEGFP-c1 & pEGFP-c1 \\
\hline
\end{tabular}

CRT-EGFP

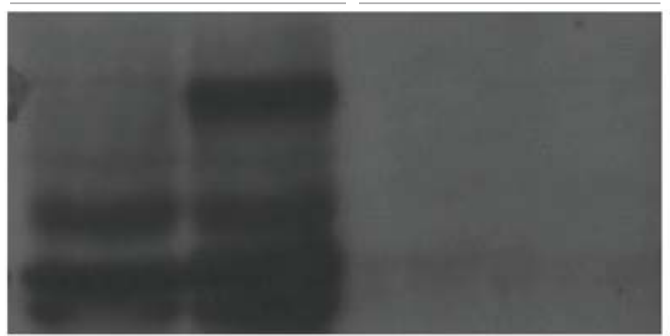

FIG. 2 Vascular endothelial growth factor (VEGF) and placenta growth factor (PlGF) mRNAs were upregulated in a calreticulin (CRT)-overexpressing cell line, and there was significantly more protein secretion in the supernatant, but CRT could barely be detected in the supernatant. a PIGF mRNA was upregulated in CRT-pEGFP-c1 cells by threefold (*** $p<0.001)$. b CRT knockdown had no effects on the PlGF mRNA level. c PlGF secretion was upregulated in conditioned media of CRT-overexpressing cells (**p $p<0.01$ ), while
PlGF secretion levels of the other three cell lines were under the detection limit $(7 \mathrm{pg} / \mathrm{ml})$. d VEGF mRNA was upregulated in CRTpEGFP-c1 cells by 1.3 -fold ( $* p<0.05$ ). (E) CRT knockdown had no effects on the VEGF mRNA level. $f$ VEGF secretion was upregulated in conditioned media of CRT-overexpressing cells $(* p<0.05)$, while VEGF secretion levels of the other three cell lines did not significantly differ. g CRT could barely be detected in conditioned media 

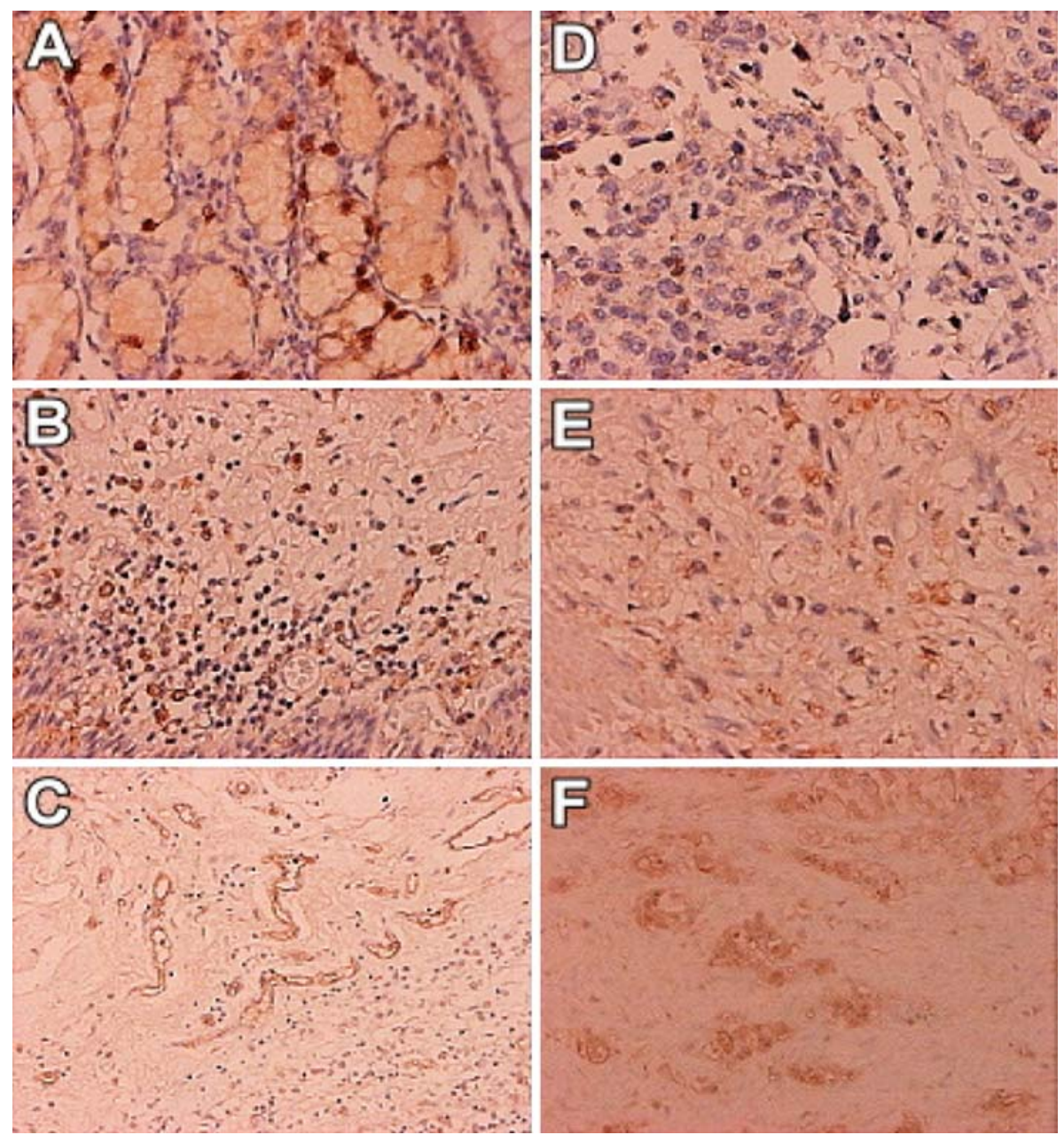

FIG. 3 Calreticulin protein expression is increased in gastric tumor tissue. In normal gastric epithelial cells, immunostaining was positive for calreticulin (a). Lymphocytes (b) and endothelial cells (c) were positively stained in some gastric tissues. Weak (d) and strong (e)

immunostaining for calreticulin was demonstrated in diffuse-type gastric cancer. Strong immunostaining for calreticulin was noted in intestinal-type gastric cancer (f)

\section{RESULTS}

\section{Calreticulin was the Most Commonly Overexpressed Gene}

A gene was defined as being overexpressed if the ratio of the detected spot intensity of the tumor to the corresponding nontumor tissue was $>1$. CRT was overexpressed in $20(67 \%)$ patients among 30 gastric cancer patients, and was the most commonly overexpressed gene in this microarray study. CRT expression was confirmed by RTPCR in 12 patients who had enough RNA left among 30 patients. Calreticulin expression levels detected in the microarray were consistent with those measured by RTPCR in nine patients (75\%) (Supplemental Fig. S1). Immunohistochemical staining demonstrated CRT was positive in cancer cells of gastric cancer tissues. The CRT expression ratio obtained from the microarrays was

significantly correlated with MVD (Pearson correlation coefficient $r=0.495, p=0.005$ ).

Construction and Confirmation of CRT Expression in CRT-Overexpressing and CRT-Knockdown Stable Cell Lines

Stable cell lines of CRT overexpression (CRT-pEGFP-c1 versus pEGFP-c1 cells) and knockdown (CRT-shRNA versus shRNA-control cells) were generated and confirmed by using qPCR and Western blot analysis (Supplemental Fig. S2).

\section{CRT Overexpression Enhanced Gastric Cancer Cell Proliferation and Migration}

Of pEGFP-c1 cells, $51.31 \%$ were in the G1 phase, whereas only $43.82 \%$ of CRT-pEGFP-c1 cells were in the G1 phase (Fig. 1a). In other words, the percentage of CRT 
TABLE 1 Correlations between clinicopathologic factors and calreticulin expression

\begin{tabular}{|c|c|c|c|}
\hline \multirow[t]{2}{*}{ Variable } & \multicolumn{3}{|c|}{ Calreticulin expression } \\
\hline & $\begin{array}{l}\text { Low } \\
(n=26)\end{array}$ & $\begin{array}{l}\text { High } \\
(n=53)\end{array}$ & $P$-value \\
\hline Gender (no. of patients) & & & 0.309 \\
\hline Male & 20 & 34 & \\
\hline Female & 6 & 19 & \\
\hline Age (years) (mean) & 62.5 & 64.3 & 0.4 \\
\hline Borrmann type & & & 0.567 \\
\hline I & 2 & 1 & \\
\hline II & 3 & 5 & \\
\hline III & 33 & 25 & \\
\hline IV & 4 & 6 & \\
\hline Lauren classification & & & 0.632 \\
\hline Intestinal & 12 & 21 & \\
\hline Diffuse & 14 & 32 & \\
\hline Serosal invasion & & & 0.013 \\
\hline Positive & 14 & 44 & \\
\hline Negative & 12 & 9 & \\
\hline Lymph node metastasis & & & 0.002 \\
\hline Positive & 13 & 45 & \\
\hline Negative & 13 & 8 & \\
\hline Helicobacter pylori infection & & & 0.799 \\
\hline Positive & 9 & 23 & \\
\hline Negative & 13 & 27 & \\
\hline Vascular invasion & & & 0.05 \\
\hline Positive & 11 & 36 & \\
\hline Negative & 15 & 17 & \\
\hline Microvessel density & & & 0.014 \\
\hline$>32$ & 7 & 28 & \\
\hline$<32$ & 19 & 25 & \\
\hline Perineural invasion & & & 0.008 \\
\hline Positive & 9 & 36 & \\
\hline Negative & 17 & 17 & \\
\hline Stage & & & 0.007 \\
\hline Ia & 7 & 1 & \\
\hline $\mathrm{Ib}$ & 4 & 3 & \\
\hline II & 2 & 5 & \\
\hline IIIa & 6 & 25 & \\
\hline IIIb & 7 & 19 & \\
\hline
\end{tabular}

overexpressing cells in the $\mathrm{S}$ and $\mathrm{G} 2 / \mathrm{M}$ phases increased from $48.69 \%$ to $56.18 \%$. Moreover, the percentage of CRT-knockdown cells in the G1 phase was elevated from $51.71 \%$ to $61.71 \%$ (Fig. 1b). These results indicate that CRT enhances gastric cancer cell proliferation. In addition, the cell migration rate of CRT-pEGFP-c1 cells was threefold higher than that of pEGFP-c1 cells, while the rate of CRT-shRNA cells was $40 \%$ lower than that of shRNAcontrol cells (Fig. 1c).
CRT Reciprocally Regulates CTGF $m R N A$ and Protein Expression

CTGF was found to be reciprocally modulated by CRT using the oligo-microarray comparing overexpressing and knockdown cell lines, and was further confirmed using qPCR and Western blot analysis (Supplemental Fig. S3).

\section{CRT Upregulated VEGF and PlGF in Gastric Cancer Cells}

We next determined whether CRT expression would affect VEGF and PIGF expression in gastric tumor cells. VEGF mRNA and VEGF protein secretion were upregulated in CRT-pEGFP-c1 cells. PIGF mRNA and PIGF protein secretion were also upregulated in CRT-pEGFP-c1 cells. However, CRT knockdown had no effects on VEGF and PIGF mRNA level. CRT was barely detected in conditioned media (Fig. 2).

\section{Correlation Between CRT Expression, MVD,} and Clinical Outcomes

CRT could be expressed in normal gastric epithelial cells (Fig. 3a), lymphocytes (Fig. 3b), and endothelial cells (Fig. 3c). CRT was positively stained in 67\% (53/79) of patients (Fig. 3d-f). The MVD of all 79 patients ranged from 5 to 68 with a mean of 32.4. We classified them into two subgroups at a cutoff point of 32 into a group with MVD $>32$ and a group with MVD $\leq 32$ for further statistical analysis. Correlations between the expression of CRT and the clinicopathologic factors are shown in Table 1. A significant correlation was found for CRT expression with serosal invasion, lymph node metastasis, perineural invasion, and MVD. Overall survival rate (76.6\%) of CRT-negative patients was significantly higher than that $(29.6 \%)$ of CRT-positive patients $(p<0.0004284)$ (Fig. 4a). In subgroup analysis, CRT was significantly associated with patient survival in the group with low MVD $(<32)$ (Fig. 4b). There was no significant survival association in patients with high MVD ( $>32)$ (Fig. 4c). Using multivariate analysis, the following were shown to be independent prognostic factors: CRT, MVD, and serosal invasion (Table 2).

\section{DISCUSSION}

CRT is now recognized to be a multifunctional protein not only in the cytoplasm but also at the cellular surface and in the extracellular environment, as it exerts a number of physiological and pathological effects. ${ }^{9}$ It is principally considered to be localized in endoplasmic reticula where it 

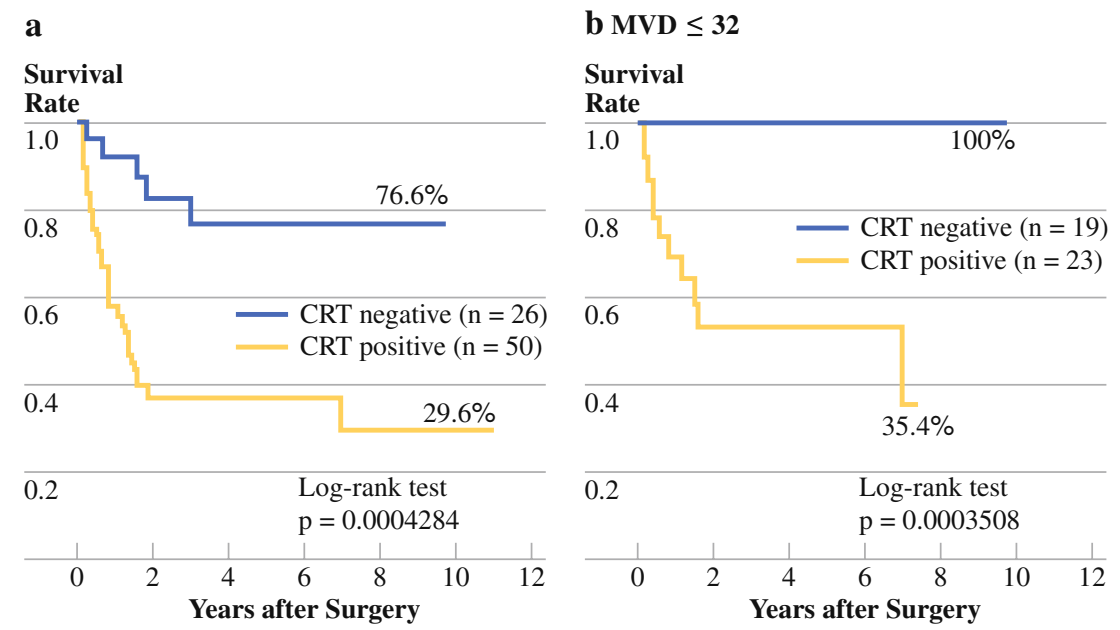

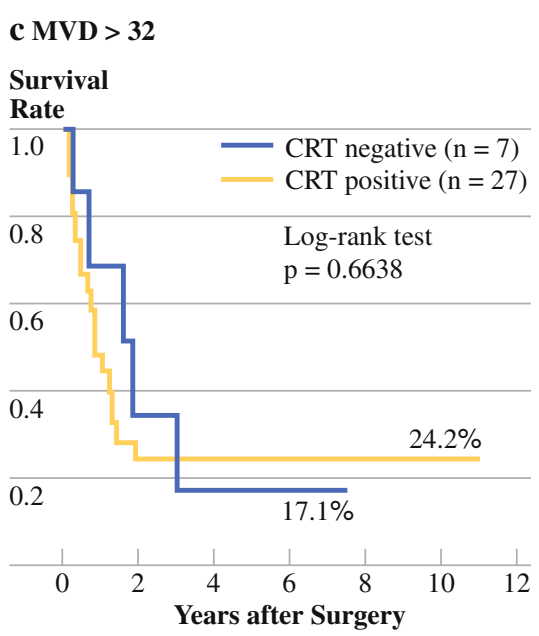

FIG. 4 a Survival curve of patients with positive and negative calreticulin expression. b Survival curve of positive and negative calreticulin expression in patients with low microvessel density

serves as a calcium-binding protein and a chaperone, and it regulates a variety of cell functions. ${ }^{10}$ In various cancers, CRT is upregulated in tumor tissues compared with in normal tissues. Increased CRT expression in hepatocellular carcinoma and colon adenocarcinoma was recently reported. ${ }^{11,12}$ It has also been reported that CRT was increased in urinary cancer tissue, and urinary calreticulin is a potential biomarker for bladder cancer. ${ }^{13}$

We observed that CRT was overexpressed in most gastric cancer tissue, and demonstrated for the first time that CRT overexpression increases cell proliferation and migration, and upregulates the expression and secretion of

TABLE 2 Clinicopathologic factors affecting survival rate by multivariate analysis

\begin{tabular}{|c|c|c|c|c|}
\hline Variable & $B$ & SE & Sig & $\exp (B)$ \\
\hline \multicolumn{5}{|l|}{ Serosal invasion } \\
\hline Negative versus positive & 1.349 & 0.625 & 0.031 & 3.853 \\
\hline \multicolumn{5}{|l|}{ Lymph node metastasis } \\
\hline Negative versus positive & 0.977 & 0.640 & 1.130 & 2.656 \\
\hline \multicolumn{5}{|l|}{ Borrmann type } \\
\hline I, II, III, IV & 0.445 & 0.661 & 0.500 & 1.561 \\
\hline \multicolumn{5}{|l|}{ Lauren classification } \\
\hline Intestinal versus diffuse & 0.387 & 0.406 & 0.340 & 1.473 \\
\hline \multicolumn{5}{|l|}{ Perineural invasion } \\
\hline Negative versus positive & -0.354 & 0.422 & 0.400 & 0.702 \\
\hline \multicolumn{5}{|l|}{ Calreticulin } \\
\hline Negative versus positive & 1.060 & 0.506 & 0.036 & 2.886 \\
\hline \multicolumn{5}{|l|}{ Microvessel density } \\
\hline$<32$ versus $>32$ & 0.915 & 0.386 & 0.018 & 2.497 \\
\hline
\end{tabular}

$B \beta$ regression coefficient; $S E$ standard error; Sig significance; $\exp (B)$ exponent $\beta$
(MVD) $(<32)$. c Survival curve of positive and negative calreticulin expression in patients with high MVD $(>32)$

the well-known proangiogenic factors VEGF and PIGF in gastric cancer cells. Meanwhile, it also regulates the cancer progression-related gene, CTGF.

It was reported that exogenous CRT, and the CRT fragment vasostatin, are inhibitors of angiogenesis that directly target endothelial cells, inhibit angiogenesis, and suppress tumor growth. ${ }^{14-16}$ Vasostatin gene therapy has proven to inhibit endothelial cell proliferation in vitro and suppress tumor growth and angiogenesis with treatment in vivo. ${ }^{17-19}$ However, that was not the case with gastric cancer. Endogenous CRT overexpression of gastric cancer cells increased the mRNA expression and protein secretion of the well-known proangiogenic factors VEGF and PIGF. On the contrary, CRT-overexpressing cancer cells barely secreted CRT to exert their antiangiogenic effect in this study. These findings could explain why high CRT expression with gastric cancer was significantly correlated with high MVD. It was also reported that vasostatintransfected neuroendocrine cells become more malignant when injected into nude mice. ${ }^{20}$ Therefore, the effect of CRT on angiogenesis may depend on cell types and intracellular or extracellular location.

CRT is essential for regulating cell adhesion via interaction with $\alpha$ subunits of integrins, which are related to endothelial and cancer cell migration, and suppression of CRT expression in rhabdomyosarcoma cells resulted in suppressed activation of matrix metalloproteinase-2 that enhances endothelial cell migration in the angiogenesis process. $^{21-24}$ Cell surface CRT is a putative mannoside lectin which triggers the spread of mouse melanoma cells. Anti-CRT antibodies confirmed this identity and block cell spreading. ${ }^{25}$ Composite reports implied that cancer cells with high CRT expression may be more invasive and angiogenic. 
CTGF is a secretory protein belonging to the $\mathrm{CCN}$ family (one among the three originally discovered members: cysteine-rich61, CTGF, and nephroblastomaoverexpressed gene). It is a multifunctional growth factor involved in wound healing, inflammation, cell adhesion, chemotaxis, apoptosis, tumor growth, and fibrosis. ${ }^{26}$ Elevated CTGF expression has been detected in various tumors. ${ }^{27-30}$ Additionally, CTGF can promote angiogenesis by regulating endothelial cell growth, migration, adhesion, and survival. ${ }^{31}$ However, recent studies showed that overexpression of CTGF in human oral squamous cell carcinoma reduces cell growth and tumorigenicity. ${ }^{32,33}$ Similar tumor growth inhibitory effects were observed in lung cancer cells in which CTGF overexpression was less angiogenic and metastatic due to blocking of the VEGF A signaling pathway. ${ }^{34,35}$ CTGF was also reported to be a key regulator of colorectal cancer invasion and metastasis, and it appears to be a better prognostic factor. ${ }^{36}$ These controversial studies suggest that CTGF may modulate diverse functions in different types of cancers, and our results showed that CRT overexpression was more angiogenic and a worse prognostic factor, and reciprocally regulated CTGF expression; theoretically, the effects of the overexpression of CTGF may be opposite to those of CRT, which is less angiogenic and a better prognostic factor in gastric cancer patients.

CRT upregulated VEGF and PIGF expressions, enhanced angiogenesis, and also increased gastric cancer cell proliferation and migration. These characters are consistent with serosal invasion, lymph node metastasis, and increased MVD, and it makes sense that CRT is an independent prognosticator, especially in patients with low MVD. Therefore, one of the potential benefits of this study may be an improved ability to identify patients at high risk for early cancer-related death. This may eventually result in the use of CRT to stratify these patients for moreaggressive adjuvant therapy, thus sparing low-risk patients from unnecessary and potentially toxic therapy. CRT, which increases tumor proliferation, progression, and angiogenesis, is a potential molecular target for anticancer therapy, and deserves further investigation.

ACKNOWLEDGMENTS Supported by grants from National Taiwan University Hospital (95A06), the National Science Council (NSC95-2314-B002-151-MY3) and the Department of Industrial Technology, Ministry of Economic Affairs (95-EC-17-A-19-S1-016), Taipei, Taiwan. The authors would like to thank the Second Core Lab at National Taiwan University Hospital for providing technical assistance and Chia-I Chen for manuscript preparation.

\section{REFERENCES}

1. Akoh JA, Macintyre IMC. Improving survival in gastric cancerreview of 5-year survival rates in English language publications from 1970. Br J Surg. 1992;79:293-9.
2. Allgayer H, Heiss MM, Schildberg FW. Prognostic factors in gastric cancer. Br J Surg. 1997;84:1651-64.

3. Golub TR, Slonim DK, Tamayo P, Huard C, Gaasenbeek M, Mesirov JP, et al. Molecular classification of cancer: class discovery and class prediction by gene expression monitoring. Science. 1999;286:531-7.

4. Alizadeh AA, Eisen MB, Davis RE, Ma C, Lossos IS, Rosenwald A, et al. Distinct types of diffuse large B-cell lymphoma identified by gene expression profiling. Nature. 2000;403:503-11.

5. Okabe H, Satoh S, Kato T, Kitahara O, Yanagawa R, Yamaoka $\mathrm{Y}$, et al. Genome-wide analysis of gene expression in human hepatocellular carcinomas using cDNA microarray: identification of genes involved in viral carcinogenesis and tumor progression. Cancer Res. 2000;61:2129-37.

6. Chen CN, Hsieh FJ, Cheng YM, Cheng WF, Su YN, Chang KJ, et al. The significance of placenta growth factor in angiogenesis and clinical outcome of human gastric cancer. Cancer Lett. 2004;213:73-82.

7. Chen JJW, Wu R, Yang PC, Huang JY, Sher YP, Han MH, et al. Profiling expression patterns and isolating differentially expressed genes by cDNA microarray system with colorimetry detection. Genomics. 1998;51:313-24.

8. Chen CN, Lin JJ, Chen J, Lee PH, Yang CY, Kuo ML, et al. Gene expression profile predicts patient survival of gastric cancer after surgical resection. J Clin Oncol. 2005;23(29):7286-95.

9. Johnson S, Michalak M, Opas M, Eggleton P. The ins and outs of calreticulin: from the ER lumen to the extracellular space. Trends Cell Biol. 2001;11:122-9.

10. Gardai SJ, McPhillips KA, Frasch SC, Janssen WJ, Starefeldt A, Murphy-Ullrich JE, et al. Cell-surface calreticulin initiates clearance of viable or apoptotic cells through trans-activation of LRP on the phagocyte. Cell. 2005;123(2):321-34.

11. Yoon GS, Lee H, Jung Y, Yu E, Moon HB, Song K, et al. Nuclear matrix of calreticulin in hepatocellular carcinoma. Cancer Res. 2000;60(4):1117-20.

12. Brunagel G, Shah U, Schoen RE, Getzenberg RH. Identification of calreticulin as a nuclear matrix protein associated with human colon cancer. J Cell Biochem. 2003;89(2):238-43.

13. Kageyama S, Isono $\mathrm{T}$, Iwaki $\mathrm{H}$, Wakabayashi $\mathrm{Y}$, Okada $\mathrm{Y}$, Kontani $\mathrm{K}$, et al. Identification by proteomic analysis of calreticulin as a marker for bladder cancer and evaluation of the diagnostic accuracy of its detection in urine. Clin Chem. 2004;50(5):857-66.

14. Pike SE, Yao L, Jones KD, Cherney B, Appella E, Sakaguchi $\mathrm{K}$, et al. Vasostatin, a calreticulin fragment, inhibits angiogenesis and suppresses tumor growth. J Exp Med. 1998;188: 2349-56.

15. Pike SE, Yao L, Setsuda J, Jones KD, Cherney B, Appella E, et al. Calreticulin and calreticulin fragments are endothelial cell inhibitors that suppress tumor growth. Blood. 1999;94:2461-8.

16. Lange-Asschenfeldt B, Velasco P, Streit M, Hawighorst T, Pike $\mathrm{SE}$, Tosato $\mathrm{G}$, et al. The angiogenesis inhibitor vasostatin does not impair wound healing at tumor-inhibiting doses. J Invest Dermatol. 2001;117(5):1036-41.

17. Jazowiecka-Rakus J, Jarosz M, Szala S. Combination of vasostatin gene therapy with cyclophosphamide inhibits growth of B16(F10) melanoma tumours. Acta Biochim Pol. 2006;53(1): 199-202.

18. Li L, Yuan YZ, Lu J, Xia L, Zhu Y, Zhang YP, et al. Treatment of pancreatic carcinoma by adenoviral mediated gene transfer of vasostatin in mice. Gut. 2006;55(2):259-65.

19. Wu PC, Yang LC, Kuo HK, Huang CC, Tsai CL, Lin PR, et al. Inhibition of corneal angiogenesis by local application of vasostatin. Mol Vis. 2005;11:28-35.

20. Liu M, Imam H, Oberg K, Zhou Y. Gene transfer of vasostatin, a calreticulin fragment, into neuroendocrine tumor cells results in 
enhanced malignant behavior. Neuroendocrinology. 2005;82(1): $1-10$.

21. Burns K, Duggan B, Atkinson EA, Famulski KS, Nemer M, Bleackley RC, et al. Modulation of gene expression by calreticulin binding to the glucocorticoid receptor. Nature. 1994;367:476-80.

22. Dedhar S, Rennie PS, Shago M, Hagesteijn CY, Yang H, Filmus $\mathrm{J}$, et al. Inhibition of nuclear hormone receptor activity by calreticulin. Nature. 1994;367:480-3.

23. Coppolino MG, Woodside MJ, Demaurex N, Grinstein S, StArnaud R, Dedhar S. Calreticulin is essential for integrin-mediated calcium signaling and cell adhesion. Nature. 1997;386: 843-7.

24. Ito H, Seyama Y, Kubota S. Calreticulin is directly involved in anti-alpha3 integrin antibody-mediated secretion and activation of matrix metalloprotease-2. Biochem Biophys Res Commun. 2001;283(2):297-302.

25. White TK, Zhu Q, Tanzer ML. Cell surface calreticulin is a putative mannoside lectin which triggers mouse melanoma cell spreading. J Biol Chem. 1995;270:15926-9.

26. Brigstock DR. The connective tissue growth factor/cysteine-rich 61/nephroblastoma overexpressed (CCN) family. Endocr Rev. 1999;20(2):189-206.

27. Wenger C, Ellenrieder V, Alber B, Lacher U, Menke A, Hameister $\mathrm{H}$, et al. Expression and differential regulation of connective tissue growth factor in pancreatic cancer cells. Oncogene. 1999;18(4):1073-80.

28. Shakunaga T, Ozaki T, Ohara N, Asaumi K, Doi T, Nishida K, et al. Expression of connective tissue growth factor in cartilaginous tumors. Cancer. 2000;89(7):1466-73.

29. Pan LH, Beppu T, Kurose A, Yamauchi K, Sugawara A, Suzuki $\mathrm{M}$, et al. Neoplastic cells and proliferating endothelial cells express connective tissue growth factor (CTGF) in glioblastoma. Neurol Res. 2002;24(7):677-83.

30. Chen PS, Wang MY, Wu SN, Su JL, Hong CC, Chuang SE, et al. CTGF enhances the motility of breast cancer cells via an integrinalphavbeta3-ERK1/2-dependent S100A4-upregulated pathway. $J$ Cell Sci. 2007;120(Pt 12):2053-265.

31. Brigstock DR. Regulation of angiogenesis and endothelial cell function by connective tissue growth factor (CTGF) and cysteinerich 61 (CYR61). Angiogenesis. 2002;5(3):153-65.

32. Moritani NH, Kubota S, Nishida T, Kawaki H, Kondo S, Sugahara $\mathrm{T}$, et al. Suppressive effect of overexpressed connective tissue growth factor on tumor cell growth in a human oral squamous cell carcinoma-derived cell line. Cancer Lett. 2003;192(2):205-14.

33. Planque N, Perbal B. A structural approach to the role of $\mathrm{CCN}$ (CYR61/CTGF/NOV) proteins in tumourigenesis. Cancer Cell Int. 2003;3(1):15.

34. Inoki I, Shiomi $T$, Hashimoto $G$, Enomoto $H$, Nakamura $H$, Makino K, et al. Connective tissue growth factor binds vascular endothelial growth factor (VEGF) and inhibits VEGF-induced angiogenesis. FASEB J. 2002;16(2):219-21.

35. Chang CC, Lin MT, Lin BR, Jeng YM, Chen ST, Chu CY, et al. Effect of connective tissue growth factor on hypoxia-inducible factor 1alpha degradation and tumor angiogenesis. J Natl Cancer Inst. 2006;98(14):984-95.

36. Lin BR, Chang CC, Che TF, Chen ST, Chen BJC, Yang CY, et al. Connective tissue growth factor inhibits metastasis and acts as an independent prognostic marker in colorectal cancer. Gastroenterology. 2005;128:9-23. 